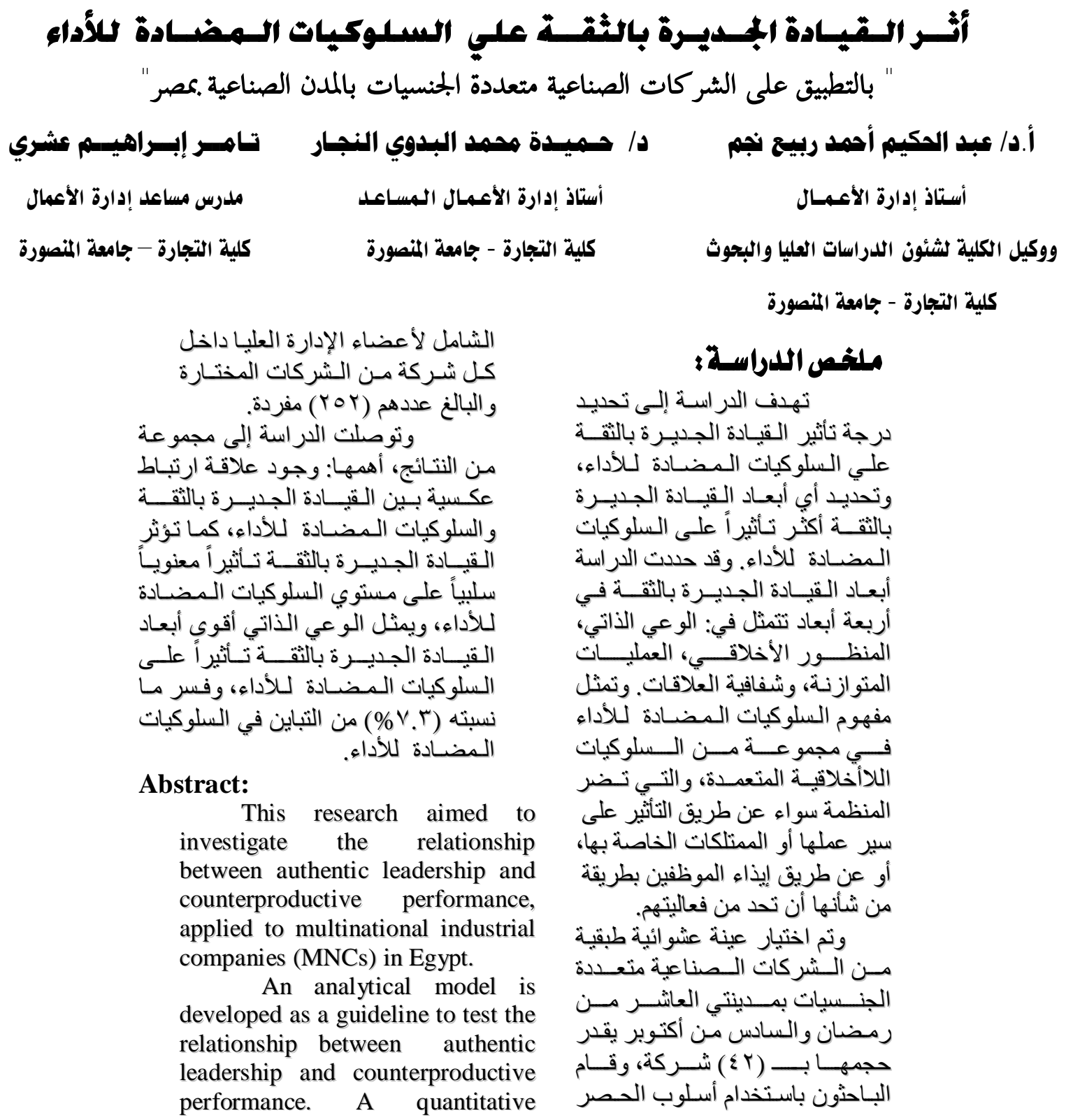


related to counterproductive performance. Also, it shows that authentic leadership has a negative effect on counterproductive performance.

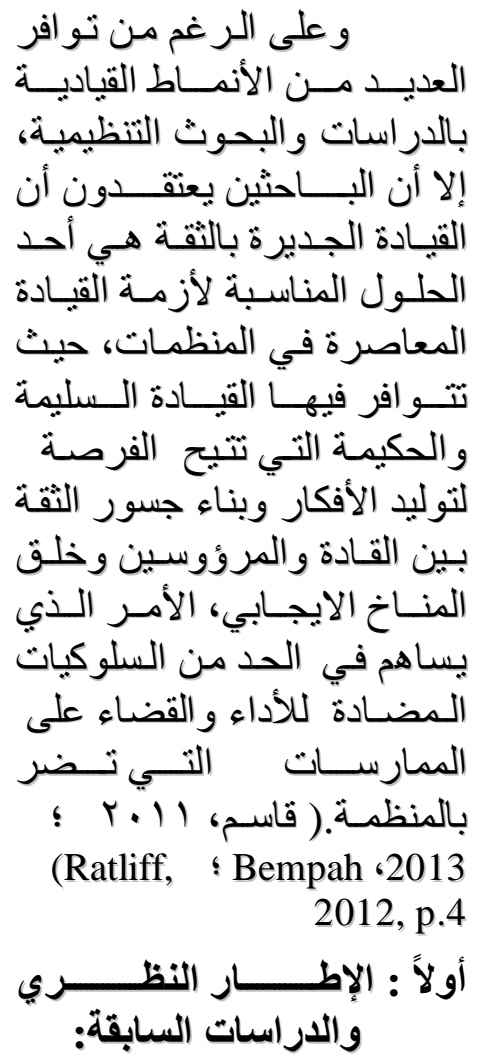

فيما يلي عرض للإطار

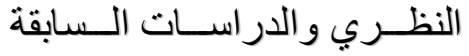

للمتغيـرات الرئيسـية فـي هـذاته

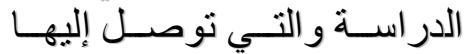

الباحثُون من خُلال مـا ورد في الدي method with deductive approach were chosen in this research. The SPSS is used to process the primary data.

The findings shows that authentic leadership is negatively

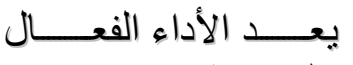

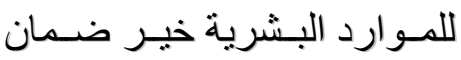

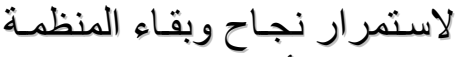

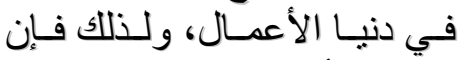

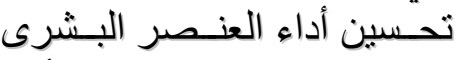

ســــعكس علــى تحــسين أداء

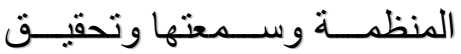

أهدافها، ومن ثم يجب على كلى كل

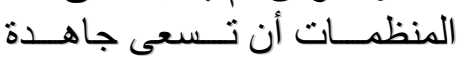

لإز الة كل المعوقات التي تحول تهول

دون الوصـول لـلأداء الـوظيفي تهولي

الجيد.(Adebayo,2012)

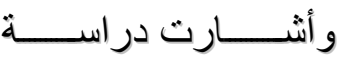

(Goodenough,2008,p.15)

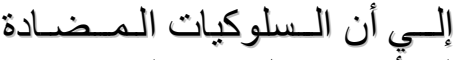

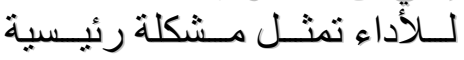

بالنسبة للمنظمات، ونتر اوح تلكي

السلوكيات مـا بين البسيطة مثنل

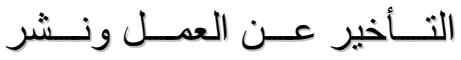

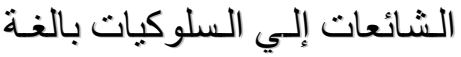

الخطورة مثل السرقة، تخريب

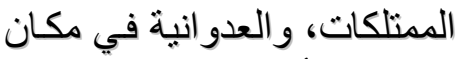

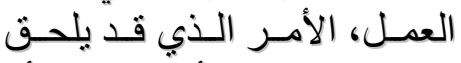

الضرر بالمنظمة أو العـاملين أو أو

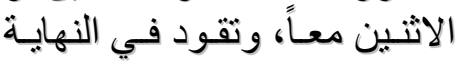
لانهيار المنظمة. 


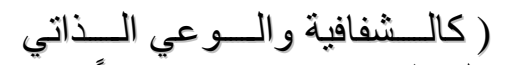

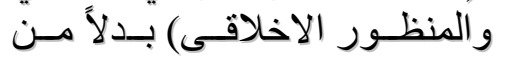

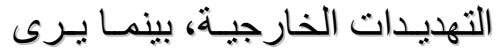

$$
\begin{aligned}
& \text { (Rego et al.,2013) } \\
& \text { الجديرة بالثقة على أنها نمط قيادي }
\end{aligned}
$$

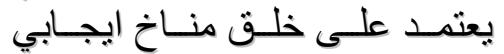

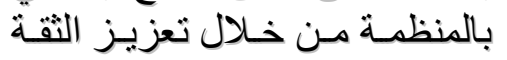

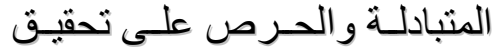

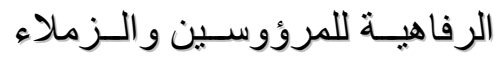

$$
\begin{aligned}
& \text { و المنظمة ككل . } \\
& \text { ويخلص البـاحثُون ممـا سبق إلى لى } \\
& \text { أن القيادة الجديرة بالثقة تعني نمط مئ البـ } \\
& \text { قيادي بتصرف الفي وفقاً للقيم و المبادئ } \\
& \text { التي يؤمن بها، لخلق مناخ ايجـابي } \\
& \text { بالمنظمة وكسب ثقة مرؤوسيه في } \\
& \text { إطار من الشفافية والوعي الذاتي مُوني }
\end{aligned}
$$

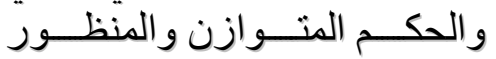

$$
\begin{aligned}
& \text { الاخلاقى. } \\
& \text { أبعاد القيادة الجديرة بالثقة : } \\
& \text { اختلف البـاحثون في البدابـة }
\end{aligned}
$$

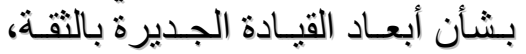

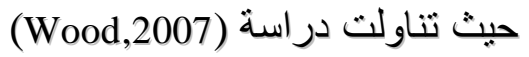

$$
\begin{aligned}
& \text { القيادة الجديرة بالثقة من خلادل ثناثة }
\end{aligned}
$$

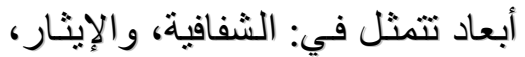

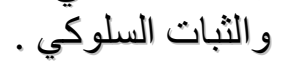

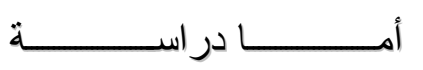

$$
\begin{aligned}
& \text { (Tuttle,2009) } \\
& \text { الجديرة بالثقة من خلال خمسة أبعاد }
\end{aligned}
$$

$$
\begin{aligned}
& \text { المر اجع ذات الصلة بمتغير ات } \\
& \text { الدراسة : }
\end{aligned}
$$

أ ـ القبـادة الجديرة بالثقـة

\section{:Authentic Leadership}

اتفــــ (Kernis,2003)

Gardner et al.,2005) (Gardner \&Schermerhorn, ؛ 2004 في تعريف القيادة الجديرة بالثقة على أنها القيادة التي تعمل وفقا للقيم والمعتقدات التي تؤمن

$$
\text { ويــذهب الـبعض }
$$

(Walumbwa et al., 2008)

إلىى أن القيـادة الجديرة بالثقـة تعتبر نمط قيادي يعتمد على كل ادة التل مسن القدرات النفـسية الايجابيـة فئة وخلق المناخ الأخلافي الإيجابي الإبي

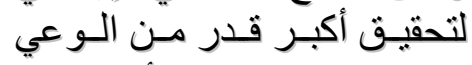

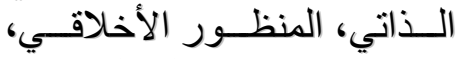

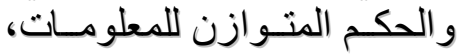

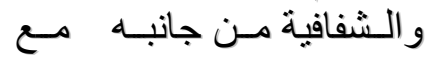

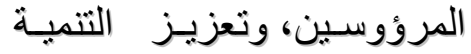
الذاتية الإيجابية .

فـي حسين عبّـر عنهـــا

بأنها (Laschinger et al.,2012)

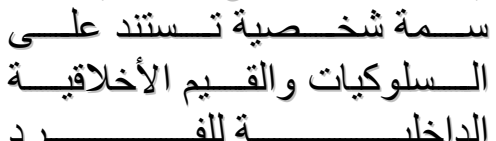




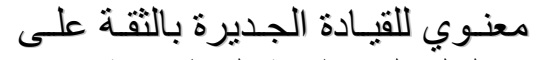

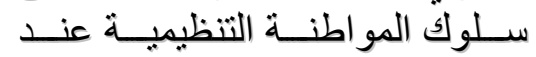
توسيط التمكين.

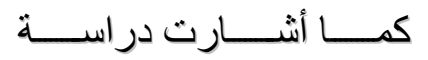

(Tuttle.,2009,p.79)

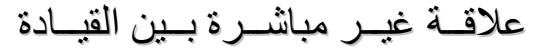
الجديرة بالثقة والانحر اف في مكان العمـل(Workplace Deviance) ووجدت تأثير سلبي معنوي للقيـادة

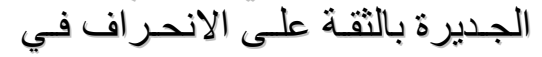

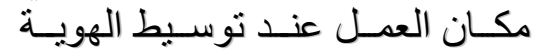

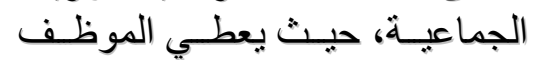

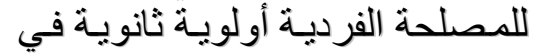
مقابل مصلحة منظمته.

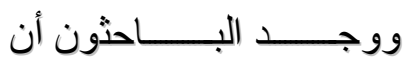

الدراسات العديدة التي تناولت القيادة

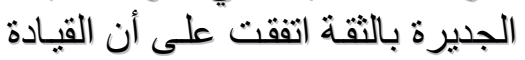

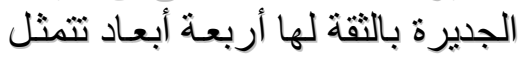

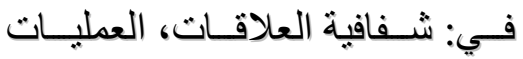

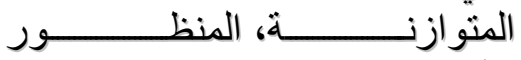
الأخلاقي، والوعي الذاتي.

(Rego et al.,2013؛ Bempah, 2013؛ Laschinger, 2012؛ Peterson et al., 2012؛ Wherry, 2012؛Sofumade, 2012؛ Cottrill ,2011؛Tapara, 2011! عalumbwa et al., 2010 , Y. 9; Walumbwa et al., 2008؛ Gardner et al.,2005؛ Kernis, 2003 )
تثمثل في : الوعي الذاتي، العمليات

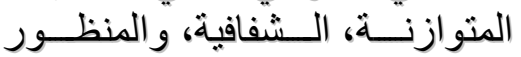
الاخلاقى ، و السلوك الجدير بالثقة . في حـين تناولـت در اســة

(Wong \&Cummings, 2009) القيادة الجديرة بالثقة من خلال سبعة

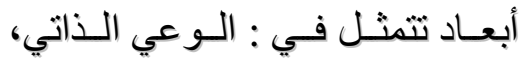

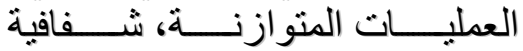

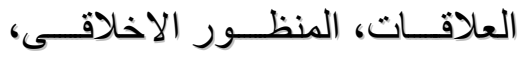
الوفاء، الدعم، التمكين. و أثــارت نتـائج در اســة

(Giallonardo et al., 2010)

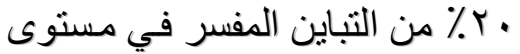
الرضا الوظيفي للممرضـات حديثي الميني التخـرج يرجـع إلى القيـادة الجـديرة

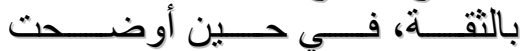

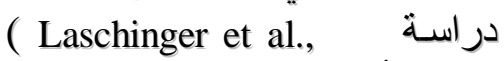
(2012 أن القيادة الجديرة بالثقة لهـا تأثير سلبي مباشر على حدوث ثقافة التمرد في مواقع العمل.

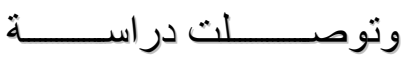

(Walumbwa et al., 2010) وجـود علاقـة مباثــرة بـين القيـادة

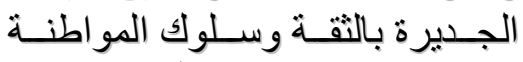

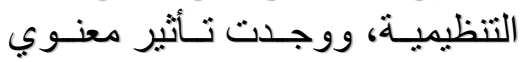

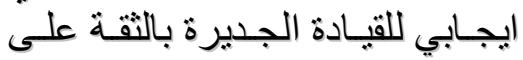
سلوك المو اطنة التنظيمية، وتوصلت التي أيضـا إلى وجود علاقة غير مباشـرة

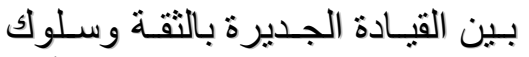
المواطنـة التنظيميـة، ووجدت بـت تـأثير 
وأن تكون لـديهم ثقـة بأنفسهم حتى بـى

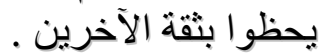

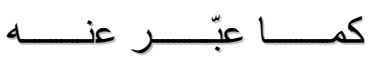

بأنســـه إدر اكله (Cottrill,2011,p.31) القادة لأنفسهم قبل إدر اكهم للآخرين، إدران

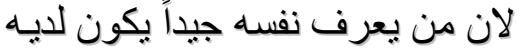
القدرة على معرفة الآخرين بسهولة بكرنة ويسر

وتوصلت الاراسات السابقة إلى وجود علاقة بين الوعي الذاتي التياتي

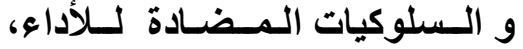
ويمكن التعرض لمسا توصلت إليها هذه النتائج على الندو التالي:

توصلت دراسة Brackette)

إلـي وجـود تـأثير معنـوي سـلبي للـو عي الذاتي على لـى

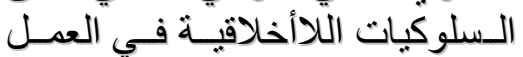

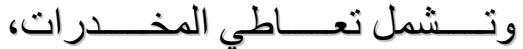

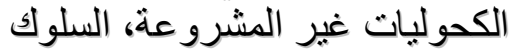

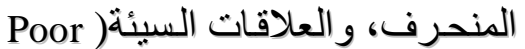
Relations ) مع الآخرين.

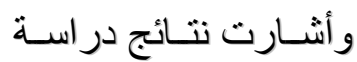
(Giallonardo et al., 2010) الو عي الذاتي لـه تأثثر سلبي مباشر آندر

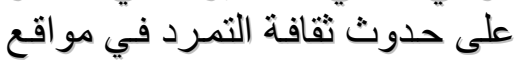

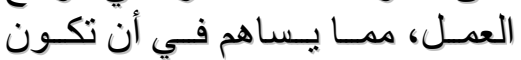

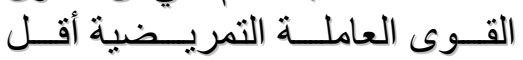
عرضة لنوايا ترك وظائفهم .
وهذا ما دعا الباحثّن إلى

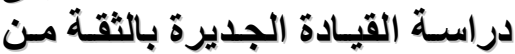

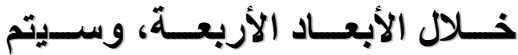
استعراض هذه الأبعاد بشيء الأبع مـن

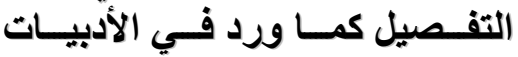
الإصة بالقيادة الجديرة بالثقة:

Self- : الـوعي الذاتي awareness

يشير (Kernis,2003) إلـي

أن الـوعي الـاني يعنسي قدرة القائد علي فهم نفسه، و إدر الك نقاط القوة التوان

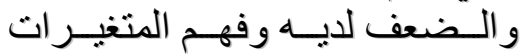

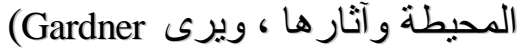

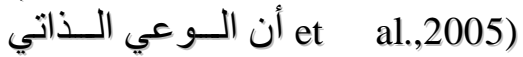

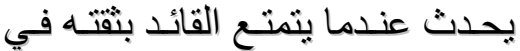
مشاعره ور غباتهـ ودو افعهه، الرقابة

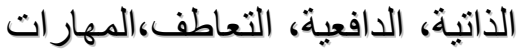
الاجتماعية، التقييم الذاني، و الو اقعية

وينظر (Walumbwa et

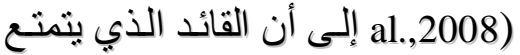

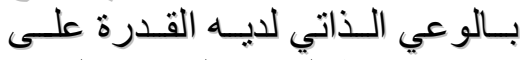

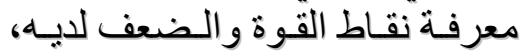
تحديــد الأهــاف، و التمـسك بــالقيم

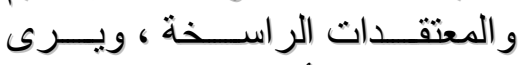
(Tate,2008)

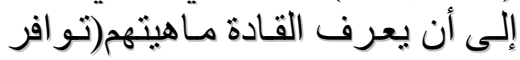

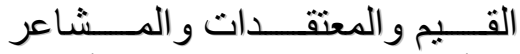
و الأهداف التي تعد بمثابـة الأسـاس الجذري لأفعـال وقـرارات القـادة)، 
معنـوي سـلبي للعمليـات المتوازنــة

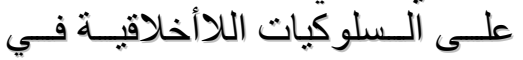

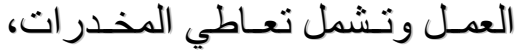
الكحوليات غير المشروعة، السلوك

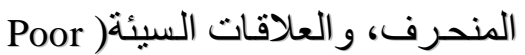
Relations و أشـارت نتـائج در اسـة

(Giallonardo et al., 2010) أن العمليـات المتوازنـــة لهــا تـأثير

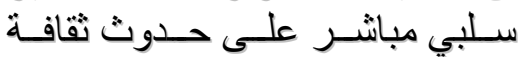
التمرد في مواقع العمل، ممـا بساهم

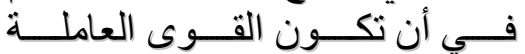
التمريضية أقل عرضــة لنو ايـا ترك الك وظائفهم .

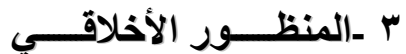

الداخلي: Internalized moral perspective

(Gardner et يسشير الأنير

(al.,2005 إلى أن المنظور الأخلاقي

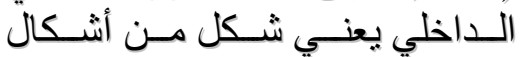

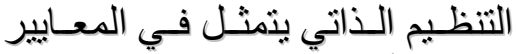
و القيم الأخلاقية الداخلية للفرد.

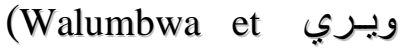

(al.,2008 إلى أن المنظور الأخلاقي

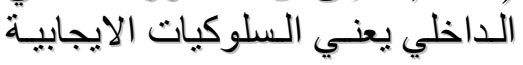

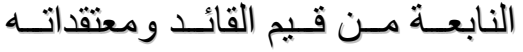
الشخصية

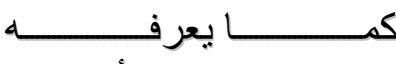

(Sofumade,2012,p.62)

\section{ب ـالعمليــات المتوازنــة :}

Balanced processing

يوضـح (Kernis,2003) أن

هـذا السلوك (العمليـات المتوازنــة)

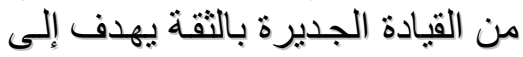
قياس مهار ات وقدرات المرؤوسين

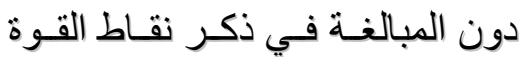

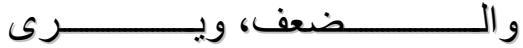
أن (Walumbwa et al.,2008)

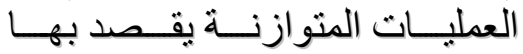

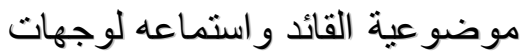
النظر المختلفة قبل اتخاذ القرار ات اتعهات ل (Cottrill, 2011,p. ويرى

(32 أن العمليــات المتوازنـــة تعنــي

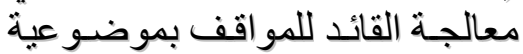

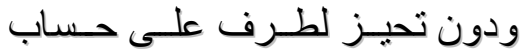
الآخر.

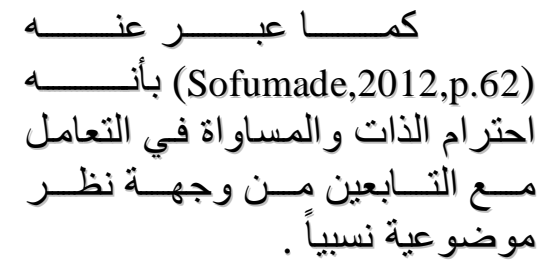

وتوصلت الدراسات السابقة

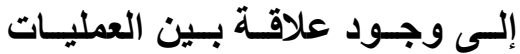

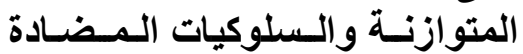

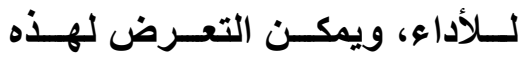
النتائج على النحو التالي:

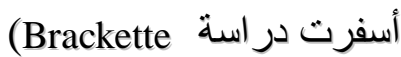

عـن وجـود تـأثير et al., 2004) 


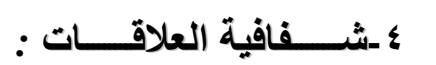

Relational transparency

ينظر ( Walumbwa et

al.,2008) إلـى أن شفافية العلاقات (لمات

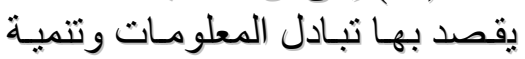

الثقة المتبادلة في العلاقات بين القائد

ومرؤوسيه.

ويسرى (Peterson et

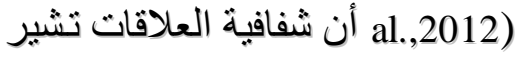

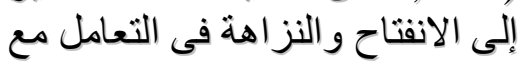

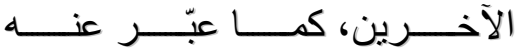

(Sofumade,2012,p.62)

السعي نحو التعاطف و الصدق في لئن

العلاقة مـع المرؤوسين لتنميـة الثقة

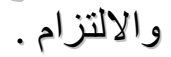

وتوصلت الاراسات السابقة

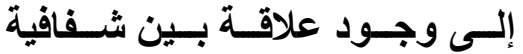

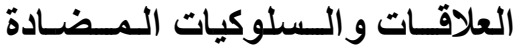

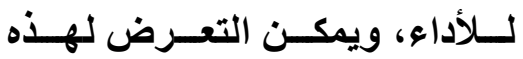
النتائج على الندو التالي:

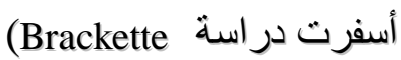

عن وجـود تـأثير et al., 2004) معنوي سلبي لشفافية العلاقات على الثى

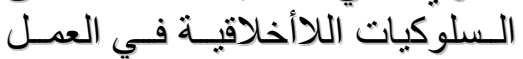

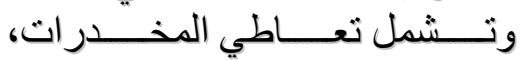
الكحوليات غبر المشروعة، السلوك

Poor المنحرف، و العلاقات السينئنة Relations ) مع الآخرين.
تصرف القائد وفقاً للقيم والمعتقدات

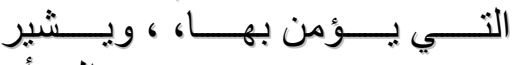
(Laschinger et al.,2012) المنظـور الأخلاقي الداخلي يظهر

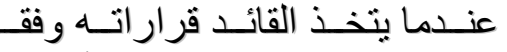
لبعض الصفات الايجابية كالأخلاق، التفاؤل، و الثقة.

وتوصلت الدراسات السابقة إلـى وجـود علاقـة بـين المنظـور

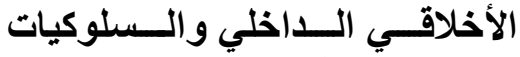

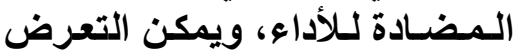
لنتـائج هذه الدراسـات على النحو التالي:

أسفرت در اسة م (Brackette)

عن وجـود تـأثير et al., 2004)

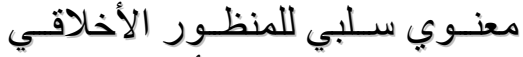

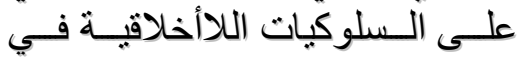

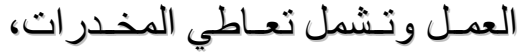

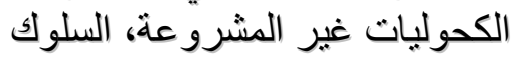

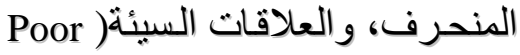
Relations ) مع الآخرين.

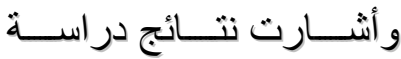

(Giallonardo et al., 2010) أن المنظور الأخلاقي له تأثير سلبي مبانر على حدوث ثقافة التمرد في لئي

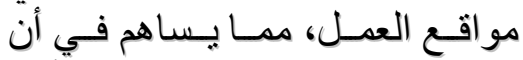
تكون القوى العاملة التمريضية أقل إنل عرضة لنوايا ترك وظائفهر . 
خـلال انتهـاك الإجـر اعات والقو اعـد

التنظيمبة.

Spector et (a)

(Dalal,2005) مع تعريف (al.,2006) للـسلوكيات الــــــــادة لــلأداء بأنهـا

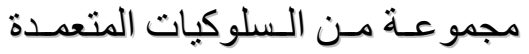

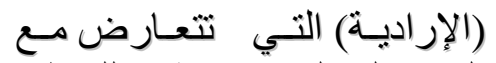

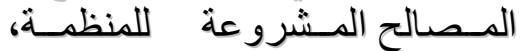
وتضر بالأطر اف أصحاب المصلحة كالعملاء وزملاء العمل والمشرفين. ويخلص الباحثون ممـا سبق البق إلى أن السلوكيات الـــضـادة لـلأداء

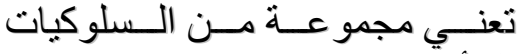

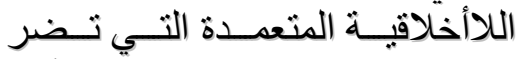
المنظمـة ســواء عـن طريـق التـأثير

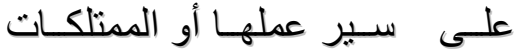

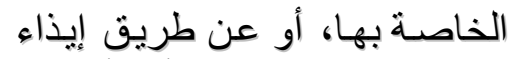
الموظفين بطريقة من شأنها أن تحد أحد من فعاليتهم .

وأشـار كل من \&unlop \&

?Peterson, 2002 ؛Lee, 2004 (Robinson \& Bennett, 1995

؛ Ansari et al.,2013) لأهم العو امل التي يجب أن نأخذ

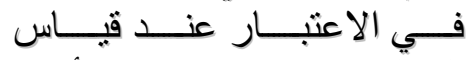

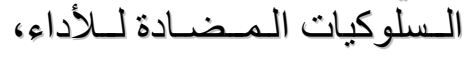
ومن هذه المؤشرات ما يلي :
و أثشارت نتـائج در اســة

(Giallonardo et al., 2010)

أن شفافية العلافـات لـه تـأثثير سـلبي

مباثر على حدوث ثقافة التمرد في لعي لئي

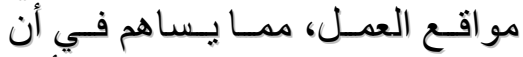
تكون القوى العاملة التمريضية أقل

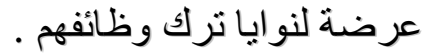

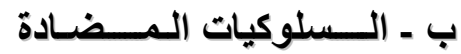

لـلأداء: Counterproductive

: Performance

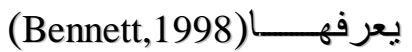

على أنهـا مجموعـة مسن السلوكيات

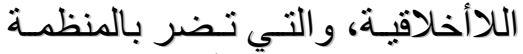

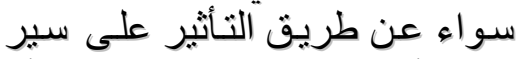

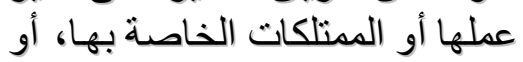
عن طريق إيذاء المـوظفين بطريقة من شأنها أن تحد من فعاليتهج .

في حين عبّر عنها Fox et

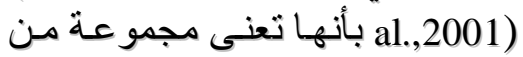
السلوكيات السلبية التي تـؤثر على التي الأداء الوظيفي للفرد أو تقلل الفعالية

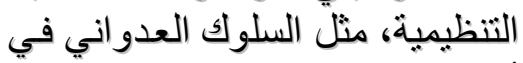

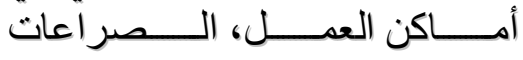

الشخصية، والتخريب و السرقة .

و اتفق(Mount et al.,2006)

مـع (Gruys\&Sackett,2003) على (إنى

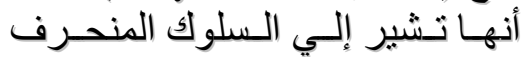

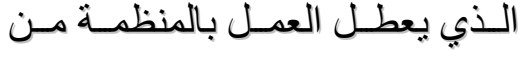




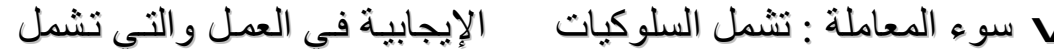

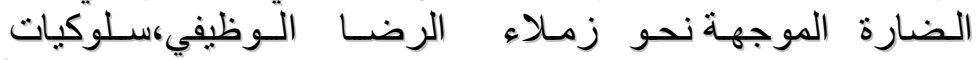

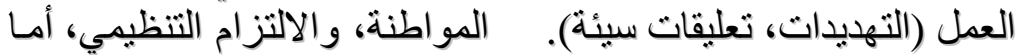

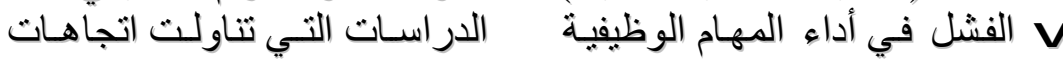

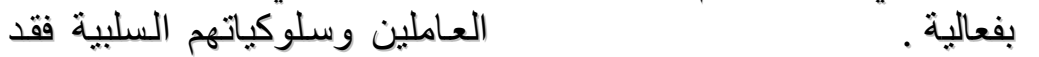

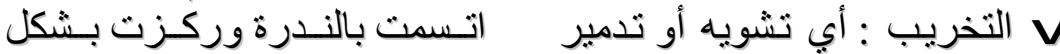

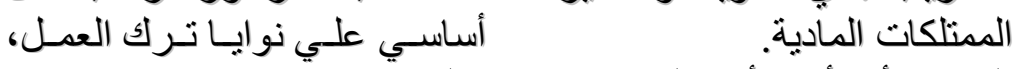

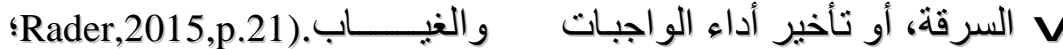

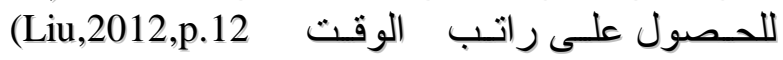

$$
\begin{aligned}
& \text { وتعـــــ الدراســـة الحاليـــة }
\end{aligned}
$$

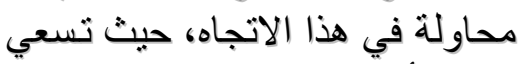

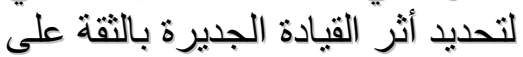

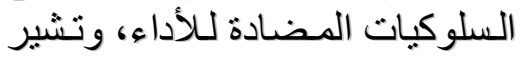

$$
\begin{aligned}
& \text { المر اجعة المبدئية للار اسـات السابقة السيقة }
\end{aligned}
$$

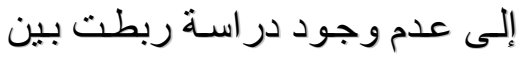

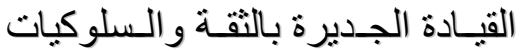

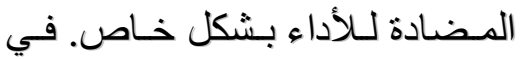

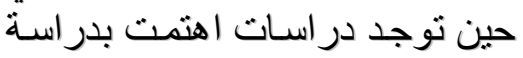

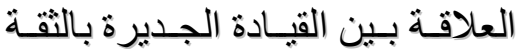

$$
\begin{aligned}
& \text { والأداء الوظيفي بشكل عام. } \\
& \text { وفي ضو و نتائج الدراسـات }
\end{aligned}
$$

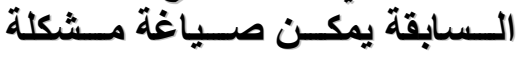

$$
\begin{aligned}
& \text { الدراسة في التساؤلين التاليين: }
\end{aligned}
$$

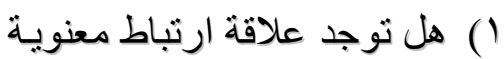

$$
\begin{aligned}
& \text { بين أبعاد القيادة الجديرة بالثية } \\
& \text { ولمستوى السلوكيات المضادئادية } \\
& \text { للأداء للمديرين بالشركات محل }
\end{aligned}
$$

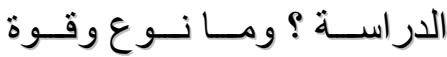

$$
\begin{aligned}
& \text { العلاقة ؟ } \\
& \text { الإضضافي. } \\
& \text { العمل في وقت مبكر ) اعتر العمل }
\end{aligned}
$$


خامسـاً: فروض الدراســة: تحقيقاً لأ هداف الدر اسة، قام الدام الباحثون بصياغة الفرضين الثاليين: (1) لا يوجـد ارتبـاط معنـوي بـين

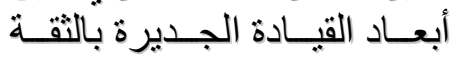
والـسلوكيات المـضادة لــلأداء

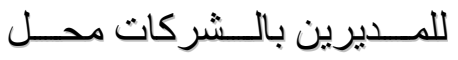
الدراسة.

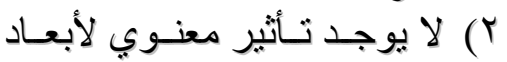

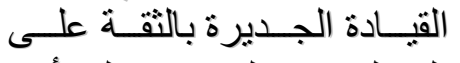
الـسلوكيات المــضـادة لــلأداء

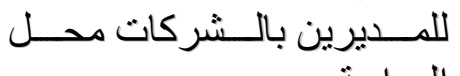

Y) هل يتـأثر مسنتوى السلوكيات

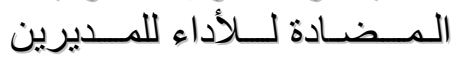

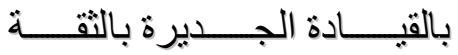
بالثركات محل الدر اسة أم لا ؟ رابعاً: أهــــاف الدراســة: تسعسى هــــه الدراســة لتحقيق الهدفين التاليين:

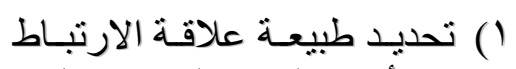
بين أبعاد القيادة الجديرة بالثقة الإدة

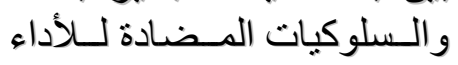

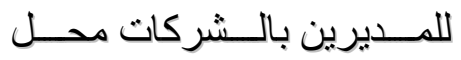

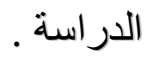
Y ب القديد نأثير أبعاد القيادة الجديرة

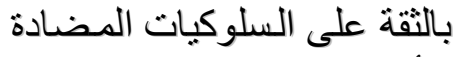
للأداء للمديرين بالشركات محل

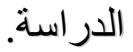

ويوضح الثكل رقم (1) التالي النموذج المقترحللعلاقات بين متغيرات الدراسة وفقاً لفروض الدراسة:

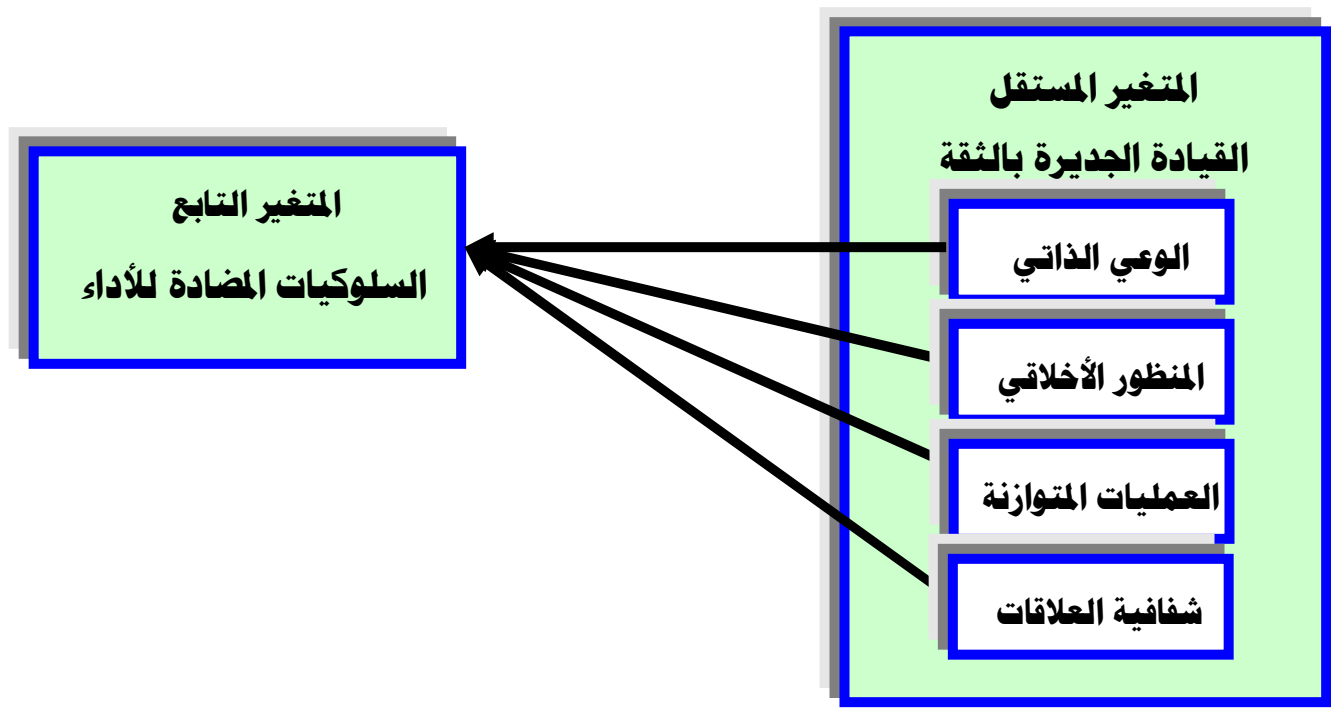

الشكل رقم(1): تصور الباحثيز للعلاقة بيز متفيرات الدر اسة اعتمادأ علي الدراسات السابقة 
أجــل تحــسين كفــاءة وفعالِـــة

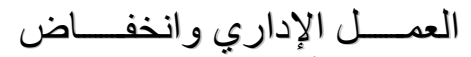
مستوي الأداء المضاد. م تقدم هذه الدراسـة للمسئولين بالـشركات متعـددة الجنـسيات بجمهورية مصر العربية إطاراً علمياً يمكن من خلاله الإلمـام

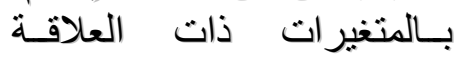

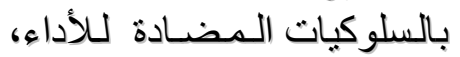

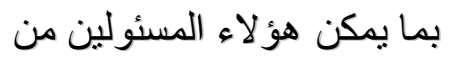

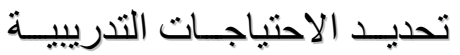

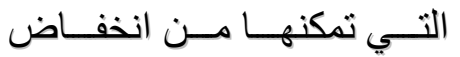

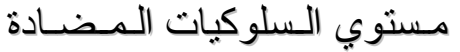

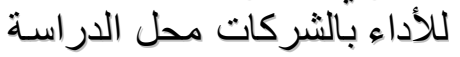

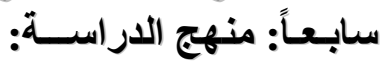

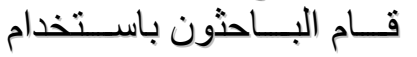

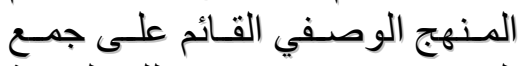

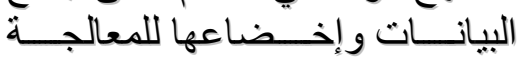
الإحصائية واستخلاص والنتائج منها،

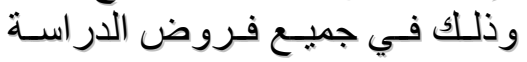

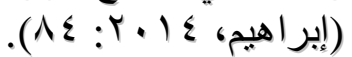

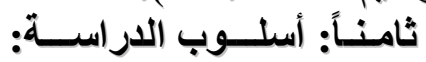
يشمل أسلوب الدراسة ما يلي:

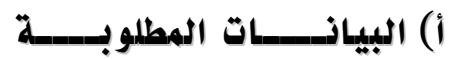
و مصادر ها :

اعتمــد البـاحثون فـي هــذه

الدراسة على نوعين من البيانات هما:

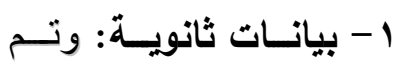

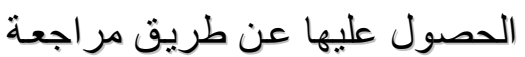

الكتب و الدر اسات و البحوث العربية مربية

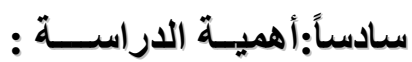

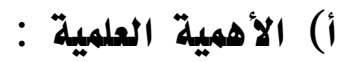

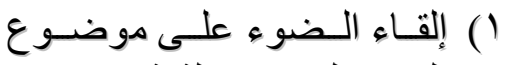

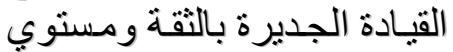

تأثيره على السلوكيات المضادة بله لبأداء.

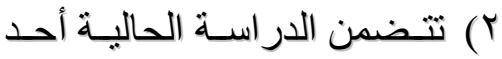

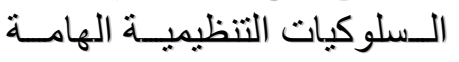

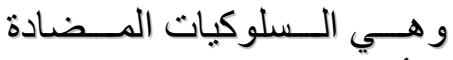

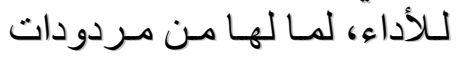

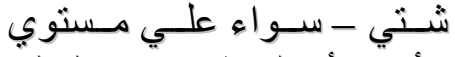
الأفر اد أو المنظمـات، وباءلي التـالي فإن الدراسة الحالية تعمل علي ولي الفي

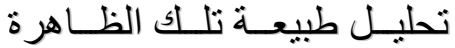

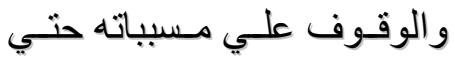

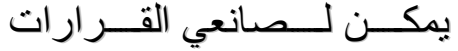
التعامل معها بطريقة علمية.

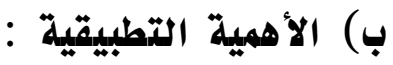

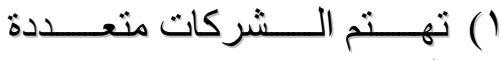

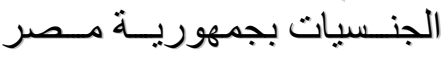
العربية بتنمية مواردها البشرية

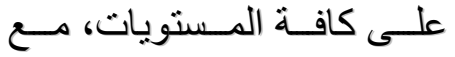
التركيـز علـى مسستوى الإدارة

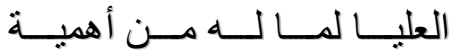

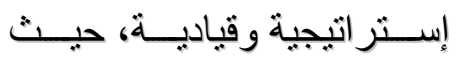
يترتب على فعالية هذا المستوى الئه

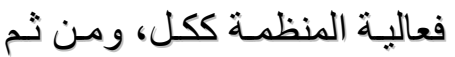
فإن معرفة نمط القيادة المسيطر المنطي علــى أعــضـاء الإدارة العليــا

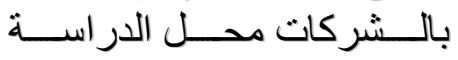

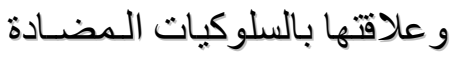
للأداء يعد ضـرورة ملحسة مـن 
ب) مجتمع وعينة الدراسـة:

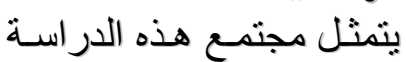

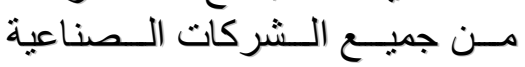

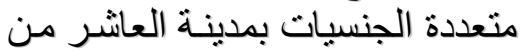
رمضان و السادس من أكتوبر و البالغ

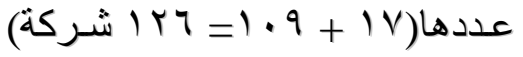

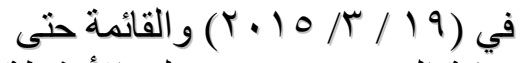
نهاية الفترة، موز عين على الأنشطة الصناعية المختلفة كما هو موضيح الاندية

$$
\text { بالجدول رقم(r). }
$$

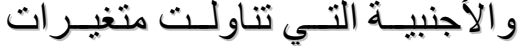

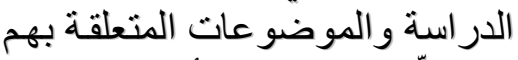

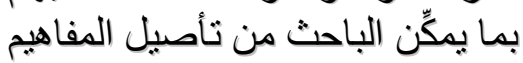
و إعداد الإطار النظري للادراسة.

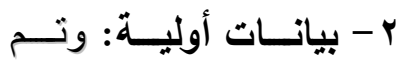
جمعها من الشركات محل الدراسـة الدانة

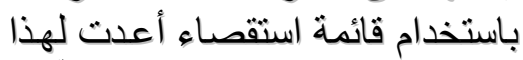

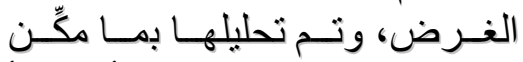
الباحثون من اختبار صحة أوضئ

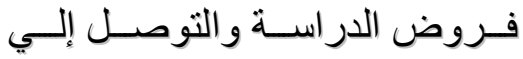

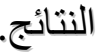

\section{جدول رقم (r)}

بيان بإجمالي الشركات متعددة الجنسيات الصناعية العاملة في مصر

\begin{tabular}{|c|c|c|}
\hline \multicolumn{2}{|c|}{ عدد الشركات في مجتمع الدراســــة } & \multirow{2}{*}{ النشاط الصناعي } \\
\hline مدينة السادس من أكتوير & مدينة العاشر من رمضان & \\
\hline & $r$ & الصناعات الخشبية \\
\hline & 9 & الصناعات الدوائية \\
\hline 0 & 17 & الصناعات الغذائية \\
\hline - & v & صناعة الغزل والنسيج \\
\hline v & ro & الصناعات الكيماوية \\
\hline r & ir & الصناعات المعدنية \\
\hline 1 & $r \leqslant$ & الصناعات الهندسية \\
\hline r & $r$ & صناعة مواد البناء \\
\hline - & 1 & صناعة التعدين \\
\hline IV & 1.9 & الإجمالي \\
\hline
\end{tabular}

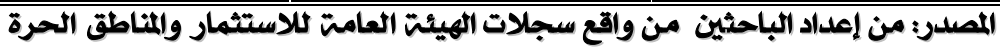

( قطاع مركز المعلومات والتوثيق ). 


$$
\begin{aligned}
& \text { البيانـات للبرنــامج تـم حسـاب } \\
& \text { وتــشمل وحـــدة المعاينــة } \\
& \text { حجم العينة وبلغ ror ror مفردة. }
\end{aligned}
$$

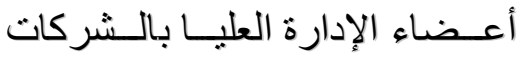

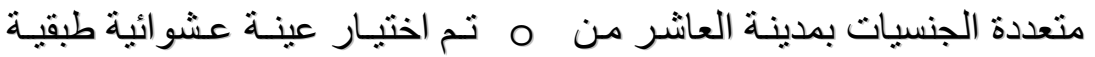

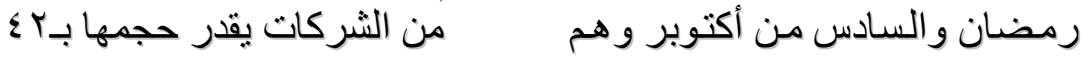

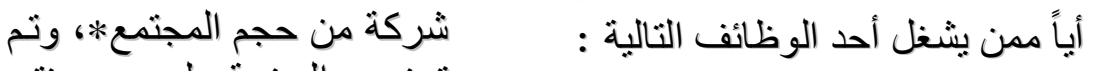

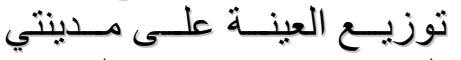

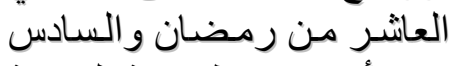

$$
\begin{aligned}
& \text { مــن أكتــوبر بطريقــة النـسبة }
\end{aligned}
$$

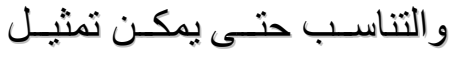

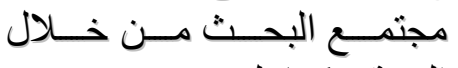

$$
\begin{aligned}
& \text { العينة ، كما يلي : البئ }
\end{aligned}
$$

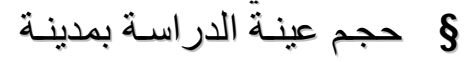

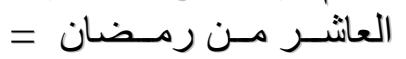

$$
\begin{aligned}
& r T=(1 r \tau \div I V) \times \leqslant r \\
& \text { شركة } \\
& \text { B حجم عينـة الدراسـة بمدينـة } \\
& \text { الـــادس مــن أكتــوبر } \\
& (1 r 7 \div 1.9) \times \leqslant r \\
& \text { = } \\
& \text { قام الباحثون بتوزيع العينـة } \\
& \text { على القطاعـات الـصناعية }
\end{aligned}
$$

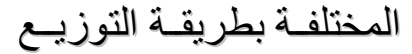

$$
\begin{aligned}
& \text { المتناسب حتى يمكن تمثيل } \\
& \text { مجتمـع البحـث مسن خـلان لمن } \\
& \text { م المدير العام }
\end{aligned}
$$

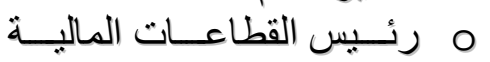

$$
\begin{aligned}
& \text { بالمنظمة } \\
& \text { o رئسيس القطاعـات التسويقية } \\
& \text { بالمنظمة } \\
& \text { م رئيس قطاع الموارد البشرية } \\
& \text { بالمنظمة فئمان } \\
& \text { م ب ربئيس قطاع الشئون الإدارية }
\end{aligned}
$$

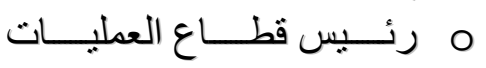

$$
\begin{aligned}
& \text { (الإنتاج) } \\
& \text { وتـم التركيزز على شـاغلي الإني }
\end{aligned}
$$

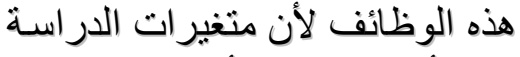

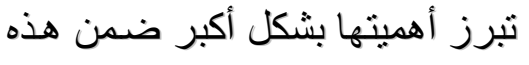

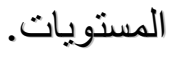

$$
\begin{aligned}
& \text { المبر احل كالتالي : } \\
& \text { * بإعتبـــار أن كــل شــركة مــن } \\
& \text { الشركات محل الاراسة يوجد بها } 1 \\
& \text { مفردات، ومسن ثم يمكن الحصول }
\end{aligned}
$$

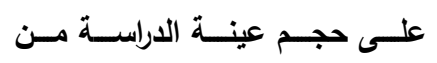

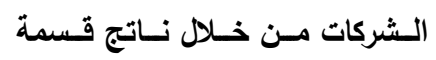

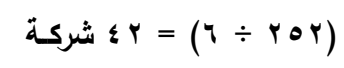




$$
\begin{aligned}
& \text { الشركات المختـارة و البالغ } \\
& \text { عددهم ror مفردة. } \\
& \text { C بلغت نسبة الاستجابة الكلية }
\end{aligned}
$$

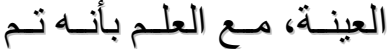

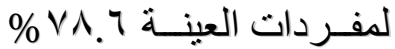

$$
\begin{aligned}
& \text { وهي نسبة مقبولة. كما هو الجينة } \\
& \text { موضـح في الجـدول رقـم فئه }
\end{aligned}
$$

\begin{tabular}{|c|c|c|c|c|}
\hline ناسبة & الصحيحة & عدد مفردات & المدينة & r \\
\hline$\% \wedge r . \wedge$ & 111 & Y17 & العاشر من رمضان & 1 \\
\hline \%rv.r & iv & rq & السادس من أكتوير & r \\
\hline$\% \vee \wedge .7$ & 191 & ror & الإجمالي & \\
\hline
\end{tabular}

ثسبت استجابت مفردات العينت على المدينتين محل الدراستة

المصدر: من إعداد الباحثين اعتمادا علي الاستمارات المستوفاة من الشركات محل الدراست..

عـد مـن الأسـاليب الإحصائية

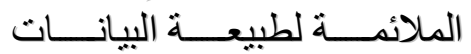

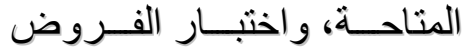

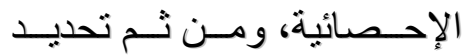

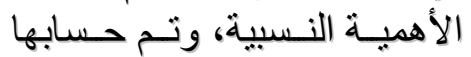

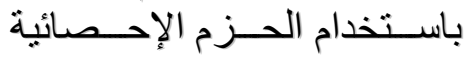

" للعلوم الاجتماعية " SPSS

(version 22)

نتائج دقيقة وموضدو عية تساعد

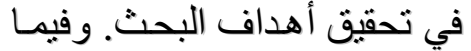

يلِي أهـم الأسـاليب الإحــــئية

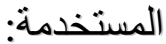

ج) أداة جمع البيانات الأولية:

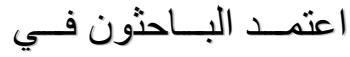

تجميع بيانـات الدراسـة الميدانيـة من مصدادر ها الأولية علي قائمة الأنة

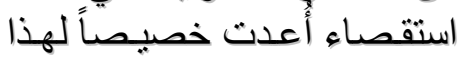

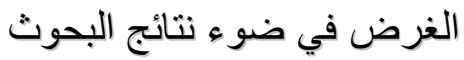

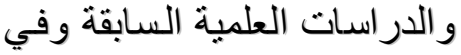

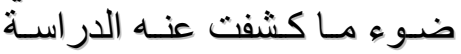

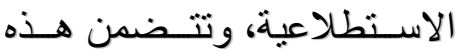

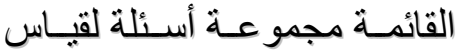

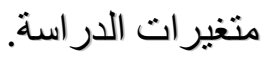
د) التحليل الإحصائي للبيانات:

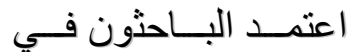

تحليل بيانات هذه الدراسـة على لي 


$$
\begin{aligned}
& \text { ثبت صدق وثبـات هذا المقياس } \\
& \text { وقد تم استخدامه في العديد من ون هذيات }
\end{aligned}
$$

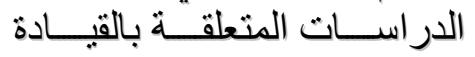

$$
\begin{aligned}
& \text { الجديرة بالثقة. }
\end{aligned}
$$

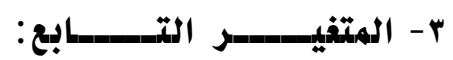

$$
\begin{aligned}
& \text { السلوكيات المضادة للأداء: }
\end{aligned}
$$

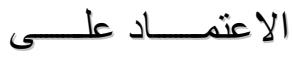

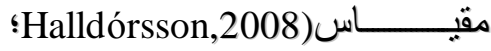

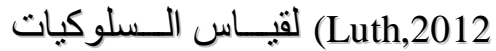

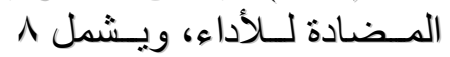
عبارات تم قيـاس الوزن النسبي لكل منها باستخدام مقياس ليكرت

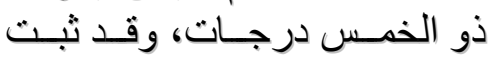
صدق وثبات هذا المقبـاس وقد تم استخدامه في العديد من الدراسيات هذات المدات

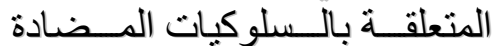
للأداء.

\section{و )ثبات وصدق المقياس:}

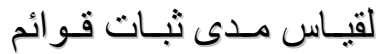

الاستقصاء كـأداة لتجميع البيانـات

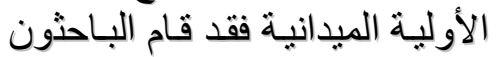
بحساب معاملات الثبات باستخدام

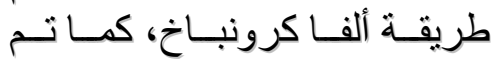

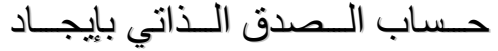

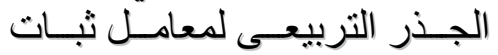
الاختبـار ، وإذا بلغتـت قيمـة معامـل

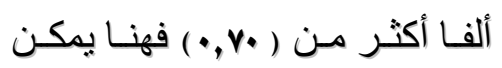

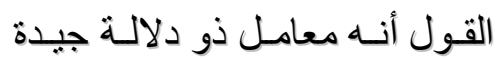
لأغر اض البحث، و الجدول التهامل دول دلالي

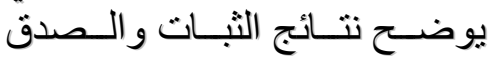
الذاتي لقائمة الاستقصاء:
( ) معامسل ألفــا كرونبـاخ

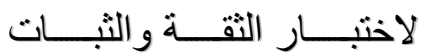
لمحتويات أداة البحث

r معامسل ارتبـاط بير سـون

وذلك لاختبار الفرض الأول

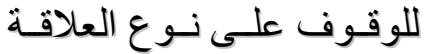

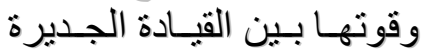

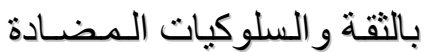
للأداء.

r) اسـتخدام أسـلوب الانحسـدار

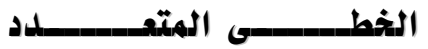

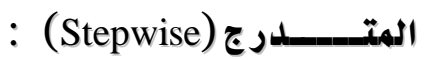
وذلك لاختبار الفرض الثناني

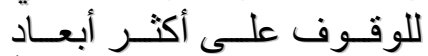

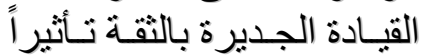

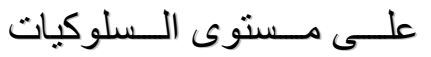
المضـادة للأداء.

هـ) قياس متفيرات الدراسـة:

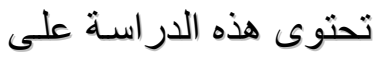
نو عين من المتغير ات تثمثل في: ا- الهتفير الهستقل: القيادة الجدليرة بالثقة:

تم الاعتماد على مقياس (Walumbwa et al.,2008)

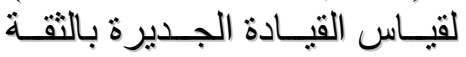

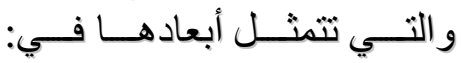

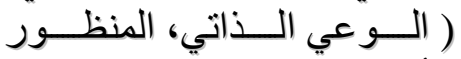

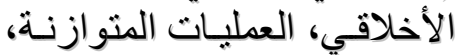
وشفافية العلاقات)، ويشمل 10 عبارة تم قياس الوزن النسبي

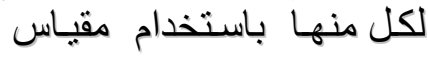
ليكرت ذو الخمس درجات، وقد باند 
جدول رقم (0)

تنائج اختبـار الثبات والصدق الذاتي لقائمة الاستقصاء

\begin{tabular}{|c|c|c|c|}
\hline معامــل الصـــق & معامــل الثبــات & عدد العبارات & المحساور الأساسية لقائمة الاستقصاء \\
\hline 9.94 &.$\wedge 7$ & 10 & القيادة الجديرة بالثقة \\
\hline$\because 94$ & .10 & $\bar{\Lambda}$ & السلوكيات المضادة للأداء \\
\hline
\end{tabular}

المصلدر: من إعداد الباحثين اعتمادا على نتائج التحليل الإحصائي.

البرنـامج الإحسائي (22

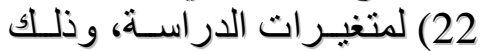
بهدف الوقوف علي شكل وطبيعة

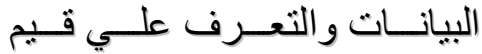

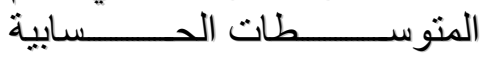
والانحر افــات المعياريـــة التـــي

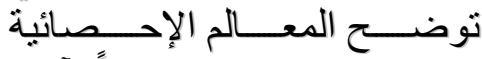

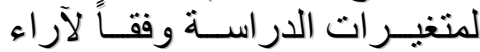
المديرين بالثركات محل الدراسة الداء

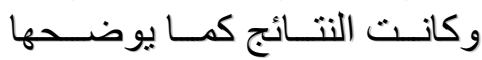
الجدول رقم (7). - (7)
وحيـث أن معامـل ألفــا

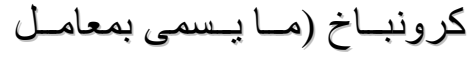

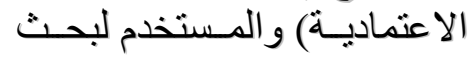
مدى إمكانية الاعتماد على ونتائج

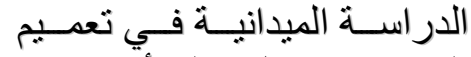

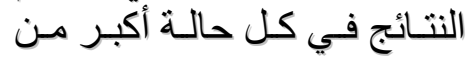

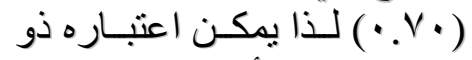

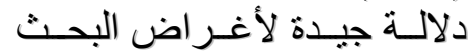
(العباسي، 999 (199 ).

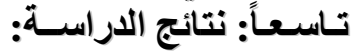
( ) التحليل الوصفي لمتغيرات التهات الاراسة:

قــام البـاحثون بــإجر اء بـاء تحليل وصـفي للبيانـات باستخدام

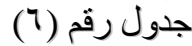

نتائج التحليل الوصفي لآر اء المديرين بالشركات محل الدراسة

\begin{tabular}{|c|c|c|}
\hline \multicolumn{2}{|c|}{ الإحصاءات الوصفية } & $L$ \\
\hline |لانحر اف المعياري & الوسط الحسابي & \\
\hline •,ory & $\$, 0$. & الوعي الذاتي \\
\hline$\cdot, 0.9$ & $\xi, \xi 0$ & المنظور الأخلاقي \\
\hline - OIr & $\varepsilon, 01$ & التو ازن و الثمول \\
\hline$\cdot, \& 9 V$ & \&, ra & شفافية العلاقات \\
\hline$\cdot,\{+1$ & $\xi, \leqslant 7$ & القيادة الجديرة بالثقة \\
\hline$\cdot, 7+1$ & $r, r$ & السلوكيات المضـادة للأداء \\
\hline
\end{tabular}

المصدر: من إعداد الباحثين من نتائج التحليل الإحصائي. 


$$
\begin{aligned}
& \text { المرؤوسين، وقد يرجع ذلك من } \\
& \text { وجهة نظر الباحثين إلي رغبة ذبنة }
\end{aligned}
$$

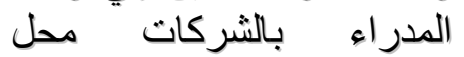

$$
\begin{aligned}
& \text { الدراسة في نشر أبعاد القيادة } \\
& \text { الجديرة بالثقة في محيط العمل فئل }
\end{aligned}
$$

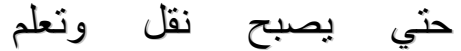

$$
\begin{aligned}
& \text { المرؤوسين لهذه الأبعاد أكثر } \\
& \text { سهولة، حيث بيمارس الإبعاد القائد } \\
& \text { الجديرة بالثقة الإدارة المبنية } \\
& \text { علي القيم. }
\end{aligned}
$$

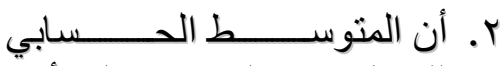

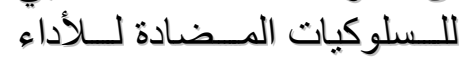

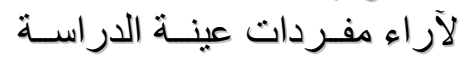

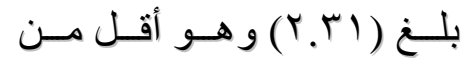

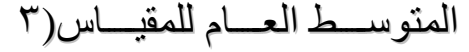

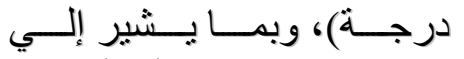

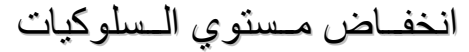

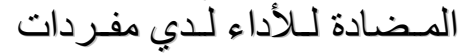

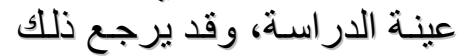

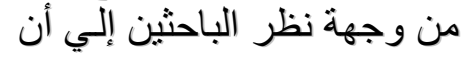

$$
\begin{aligned}
& \text { مفـردات عينـة الدر اســة لــديها }
\end{aligned}
$$

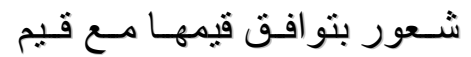

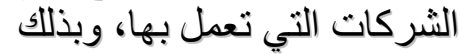

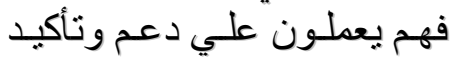

$$
\begin{aligned}
& \text { ذللك، بالإضافة إلي أن تجسيدهم داءئ }
\end{aligned}
$$

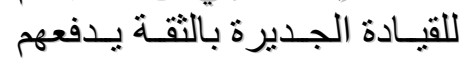

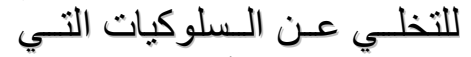

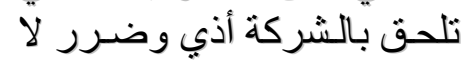

$$
\begin{aligned}
& \text { يتسق مع مثل هذا التوجه. }
\end{aligned}
$$

$$
\text { يتضح ما يلي. }
$$$$
\text { 1. أن المتوسط الحسابي للقيادة }
$$$$
\text { الجديرة بالثقة لآراء مفردات }
$$

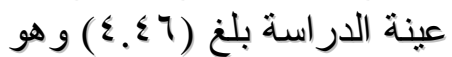

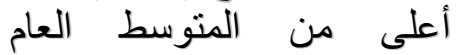$$
\text { للمقياس( آس درجة)، وبما يشير }
$$$$
\text { إلي أن درجة ممارسة مديري }
$$$$
\text { الثركات محل الاراسة لنمة لنمارئ مديري }
$$

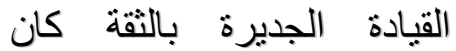

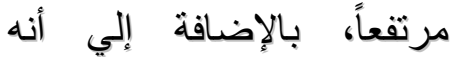
وبالنظر إلي قيم المتوسطات الحسابية لأبعاد القيادة الجديرة بالثقة، يتضح وجود تفاوت في لإداء الجيرة

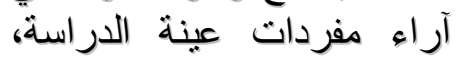

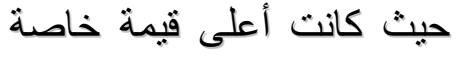
ببعد العمليات المتوازنة الثيث حيثة بلغت قيمة المتوسط الحسابي لها (

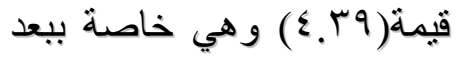
شفافية العلاقات، وهي وهو ما يشير

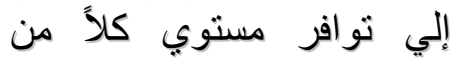

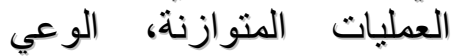
الذاتي، العنظيات المنظور الأخلافي، وشفاقية العلاقات بثكل مرثفع الاتيك لدي مفردات عينة الدراسة، مما بدل علي ثقة الفي المديرين

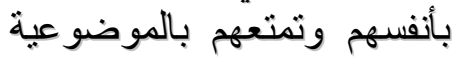
ومر اعاة التوازن في التعاملات بونه

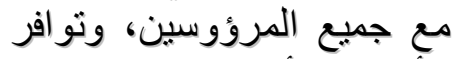

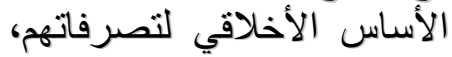

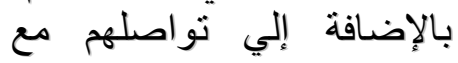


الجديرة بالثقة والسلوكيات

المضادة للأداء للمديرين والملين

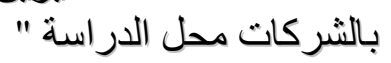

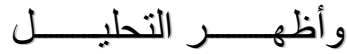

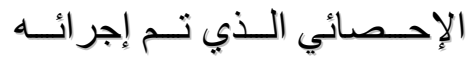

باستخدام معامل ارثباط بيرسون إندان

النتائج الخاصة بهذه العلاقة كمـا هو موضح في جدول رقم (V):

r) اختبار فروض الاراسة:

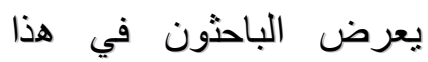

الجزء نتائج اختبار فرضي الدراسة

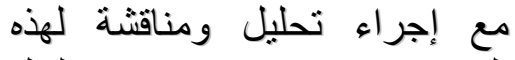

النتائج، ونم تقسيمها حسب تسلسل

هدفي وفرضي البحث كما يلي :

الفرض الأول وينص على الجى

أنه " لا لا يوجد ارتباط

معنوي بين أبعاد القيادة

جنول رقم (v)

معاملات الارتباط بين متغيرات الدراسة.

\begin{tabular}{|c|c|c|}
\hline \multicolumn{2}{|c|}{ المتفير التابع: السلوكيات المضادة للأداء } & \multirow{2}{*}{ ( البعاد المتفير المستقل الجيدة بالثقة) } \\
\hline الدلالة مستوى Sig & معامل الارتباط & \\
\hline$\cdot, \cdots$ & $* *, r r \mid$ & الوعـي الذاتي \\
\hline$\bullet, \cdot+1$ & $* *_{\bullet}, r \leqslant 1=$ & المنظور الأخلاقي \\
\hline$\cdot, \cdot\{7$ & $*, 1 \leqslant r$. & العمليات المتوازنة \\
\hline$\cdot, 1 \cdot \varepsilon$ & $\cdot, 117$ & شفافية العلاقات \\
\hline$\bullet,+\bullet$ & $* *, r \leqslant \Lambda$ - & القيادة الجديرة بـالثقة ككل \\
\hline
\end{tabular}

* معنوية عند مستوى ه ., .

** مغنوية عند مستوى 1 .,.

المصدر : من إعداد الباحثين من نتائج التحليل الإحصائي.

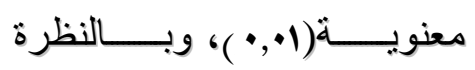

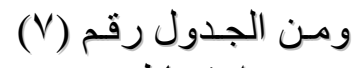

الفاحصة لكل من قيم "معاملات

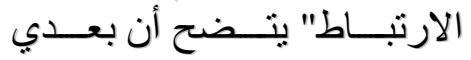

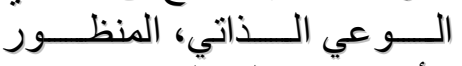

الأخلافي - كل على حدة يسهم المنظئ

يتـضـح وجـود ارتبــاط معنـوي

سلبي بين القيادة الجديرة بالثئة

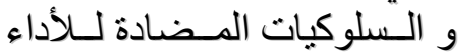

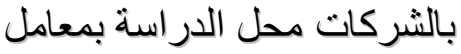

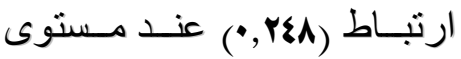


ارتبـــاط معذوبـــة بــين شـــافية العلاقات والسلوكيات المـضادة

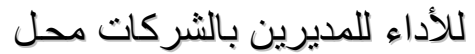

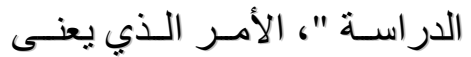

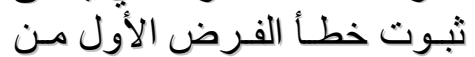
فروض الدراسة جزئياً.

الفرض الثاني وينص على m أنه " لا يوجد تأثير معنوي لأبعاد القيادة الجديرة بالثير مبالثة

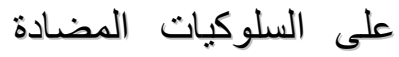
للأداء للمديرين بالثركات الثركيات محل الدراسة" لمدئ

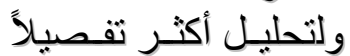
حول أبعاد القيادة الجديرة بالثقة

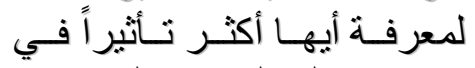

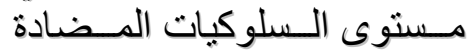

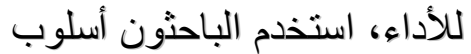

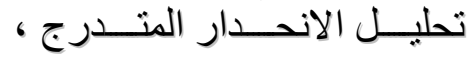

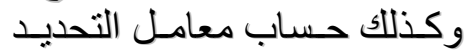

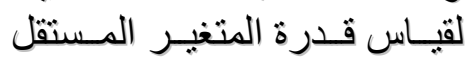
على تفسير التغيرات التي تحدث

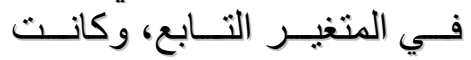

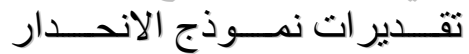

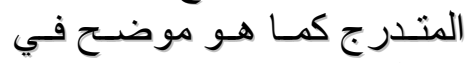
جدول رقم (^):
معنويــاً فــي خفــ مسـستوى السلوكيات المضادة للأداء عند فئد

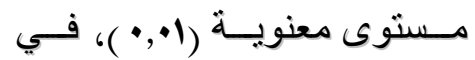
حين أن بعد العمليات المتوازنـة اهن

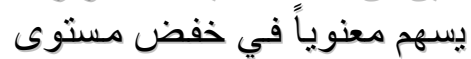
السلوكيات المضادة للـأداء عند فئد مستوى معنويـة (0., • )، بينمـا

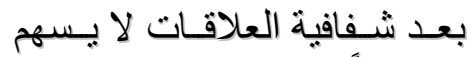

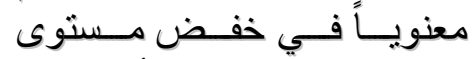
السلوكيات المضادة للادداء، كمـا فيسا

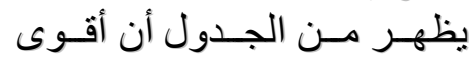

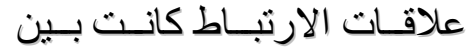

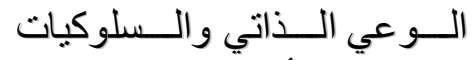

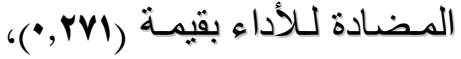
يليهــــا علاقـــة الارتبــــاط بـــين المنظور الأخلاقي والسلوكيات

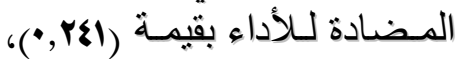
ثم جـاءت في المرتبـة الأخيرة

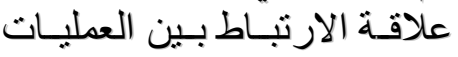
المتوازنـة و السلوكيات المضادة العاديات

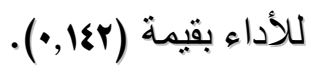

وبنـــاءً علــــى النتــــائج

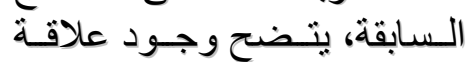

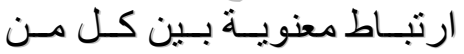

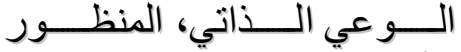

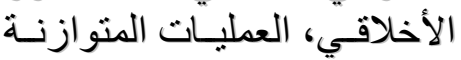
و الـسلـوكيات المــــادة لــلأداء

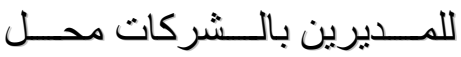

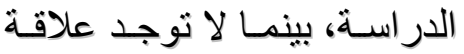


جدول رقم (^)

تقديرات نموذج الانحدار المتدرج لبيان أكثر أبعاد القيادة الجنيرة بالثقة تأثيراً في

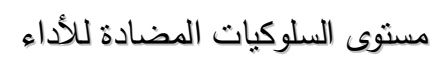

\begin{tabular}{|c|c|c|c|c|c|c|}
\hline \multicolumn{4}{|c|}{ تقديرات نموذج الانحدار المتدرج } & \multirow{2}{*}{ أبعاد القيادة الجديرة } & \multirow{3}{*}{$\begin{array}{c}\mathbf{F} \\
\text { (sig.) } \\
10,019 \\
* * ., \cdots\end{array}$} & \multirow{3}{*}{$\begin{array}{c}\text { معامل التحديد } \\
R^{2} \\
\cdot, \cdot r\end{array}$} \\
\hline Sig. & $\mathbf{T}$ & B & & & & \\
\hline$* *_{,}, \cdots$ & r,qrq - & •, & الوعي الذاتي & الوعي الذاتي & & \\
\hline
\end{tabular}

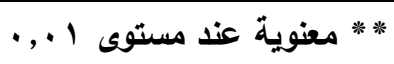

المصدر : من إعداد الباحثين من واقع التحليل الإحصائي لبيانات قائمة الاستقصاء.

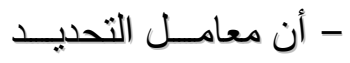

(إ)

مساهمة الوعي الذاتي في تفسير

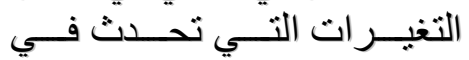

السلوكيات المضادة للـادداء هي

\% V,r

- يتـضح مـن الجـدول

أن إنـارة معامل الانحدار سالبة،

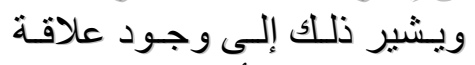

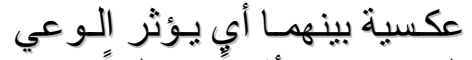

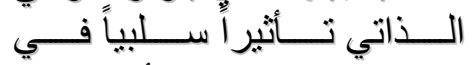

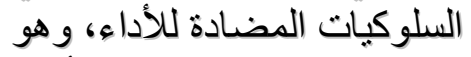

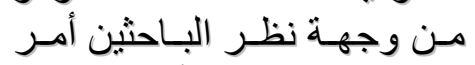

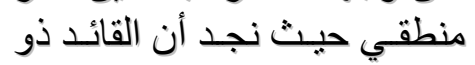

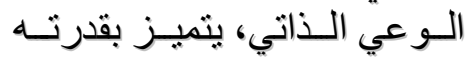

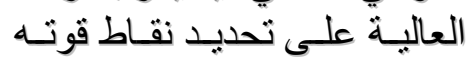

وضعفه، وفى نفس الوقت تكون

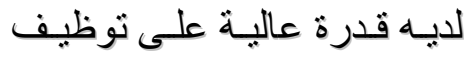

نقــاط القـوة والاسـتفادة منهــا، تونـا،

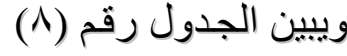

ما يلي: أنسه مسن بـين الأبعـاد

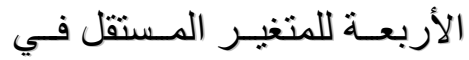

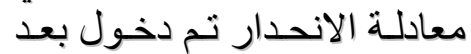

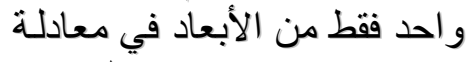

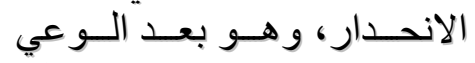

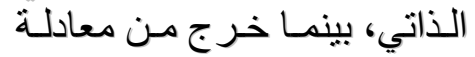

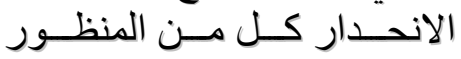

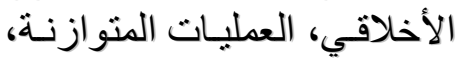

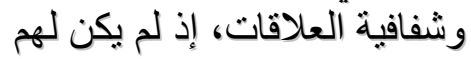

دور هــام فـي تفـسير بيانـات التهات

المتغير التابع.

ـ أوضحت نتـائج تحليل

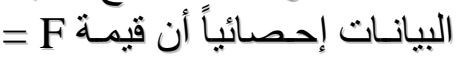

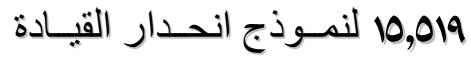

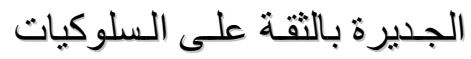

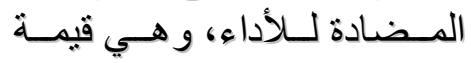

معنوية عند مستوى (1+,•). 


$$
\begin{aligned}
& \text { (r) ضـرورة اهنمـام الـشركات } \\
& \text { متعددة الجنسيات بتصميم وثتفيذ الريذ } \\
& \text { البرامج التدريبية التي تعمل علي لتي } \\
& \text { تنميـة ســلوكيات القيـادة الجـديرة }
\end{aligned}
$$

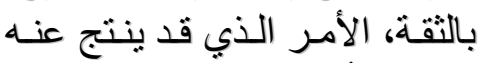

$$
\begin{aligned}
& \text { فيما بعد أن تترجم سلوكيات القادة }
\end{aligned}
$$

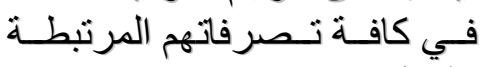

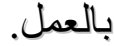

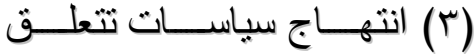

$$
\begin{aligned}
& \text { بالموارد البشرية مبنية على قدر }
\end{aligned}
$$

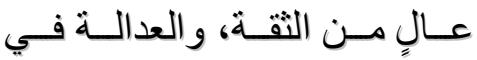

$$
\begin{aligned}
& \text { التعاملٍ مع الجميع، وتقديم الدعم ولدي } \\
& \text { المادي و المعنوي للعاملين. } \\
& \text { (ع ) تنظـيم الـدورات و النـدوات } \\
& \text { التثقيفية التي تظهر الآثار السلبية }
\end{aligned}
$$

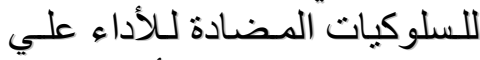

$$
\begin{aligned}
& \text { المنظمة و علي العمال أنفسهح. }
\end{aligned}
$$

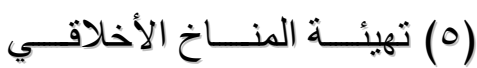

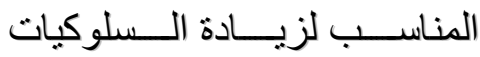

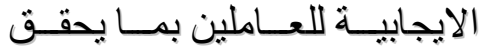

$$
\begin{aligned}
& \text { أهداف المنظمة. }
\end{aligned}
$$

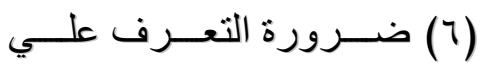

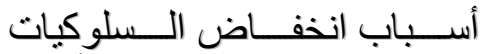

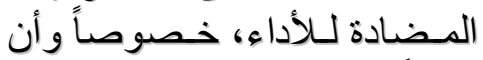

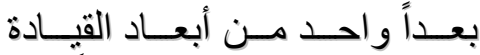

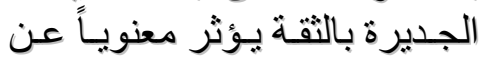

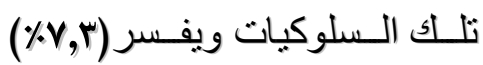

$$
\begin{aligned}
& \text { منها، و هذا يعني وجود (\% (\%,V)، }
\end{aligned}
$$

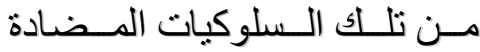

$$
\begin{aligned}
& \text { للأداء تحتـاج إلي تفسير وتحديد }
\end{aligned}
$$

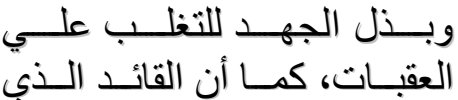

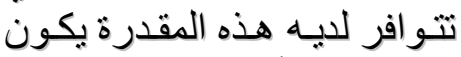

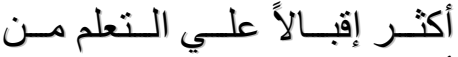

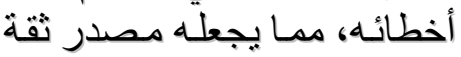

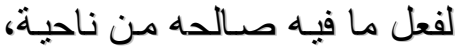

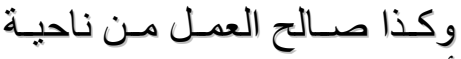

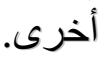

$$
\begin{aligned}
& \text { وبنـــاءة علــــى النتـــائج }
\end{aligned}
$$

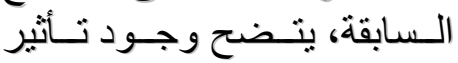

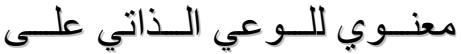

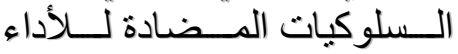

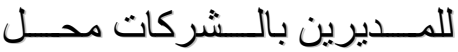

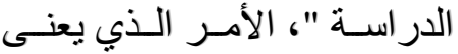

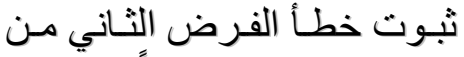

$$
\begin{aligned}
& \text { فروض الدراسة جزئياً. } \\
& \text { علي النحو التالي: }
\end{aligned}
$$




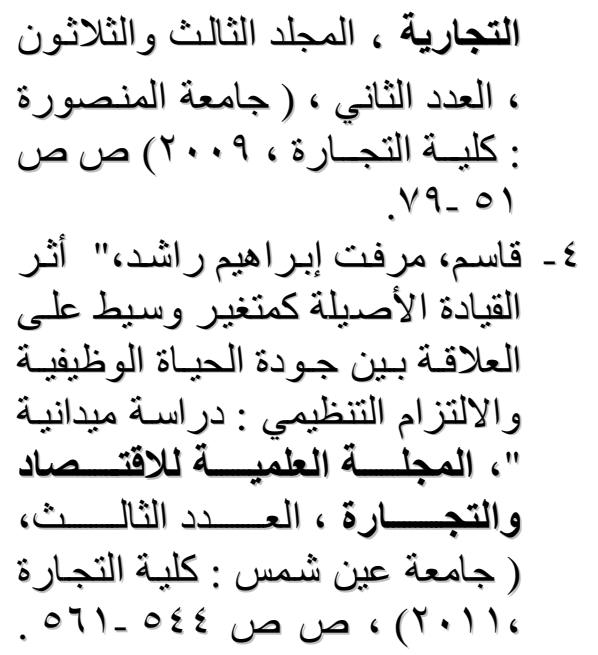

And Employee Deviance: A Proposed Model And Empirical Test ", Journal of Organizational Behavior, Vol. (20), 1999, pp: 10731091.

8- Bennett, R., " Taking The Sting Out of The Whip: Reactions to Consistent Punishment for Unethical Behavior ", Journal of Experimental Psychology, Vol. (4),No,(3), 1998, pp: 248-262.

9- Brackette, M.\& Mayer, J.\& Warner, R.," Emotional Intelligence and Its Relation To Everyday Behaviour ", Personality and Individual Differences, Vol. (36),No,( 6), 2004, pp: 1387-1402.

10- Bukhari, Z.\& Ali, U., " Relationship between Organizational Citizenship Behavior \& Counterproductive Work Behavior in the

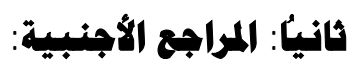

5- Adebayo, J.\& Olayide, R.\& Saheed, O., " Influence of Leadership Styles and Emotional Intelligence on Job Performance of Local Government Workers in Osun State, Nigeria, " Journal of Alternative Perspectives in the Social Sciences, Vol. (3) ),No,(4), 2012, pp. 973-996.

6- Ansari, M.\& Maleki, S.\& Mazraeh, S.\& Arab-Khazaeli, H., "Individual, Job, and Organizational Predictors of Counterproductive Work Behavior", Journal of Basic and Applied Scientific Research, Vol. (3),No,(4), 2013, pp: 78-86.

7- Aquino, K.\& Lewis, M.\& Bradfield, M.," Justice Constructs, Negative Affectivity, 
Behavior, Vol. (25),No,(1), 2004, pp: 67-80.

15- Fox, S.\& Spector, P.\& Miles,D.," Counterproductive Work Behavior (CWB) in Response to Job Stressors and Organizational Justice: Some Mediator and Moderator Tests for Autonomy and Emotions", Journal of Vocational Behavior, Vol. (59),No,( 3), 2001, pp: 291-309.

16- Gardner, W.\& Avolio, B.\& Luthans, F.\& May, D.\& Walumbwa F., " Can You See The Real Me?" A Self-Based Model Of Authentic Leader And Follower Development ", The Leadership Quarterly, Vol. (16),No, (3), 2005, pp. 343-372.

17- Gardner, W.\& Schermerhorn, J.," Unleashing Individual Potential Performance Gains Through Positive Organizational Behavior and Authentic Leadership", Organizational Dynamics, Vol. (33),No, (3), 2004, pp. 270-281.

18- Giallonardo, L.\& Wong, C.\& Iwasiw, C., " Authentic leadership of Preceptors: Predictor of New Graduate Nurses' Work Engagement and Job Satisfaction ", Journal of Nursing Management, Vol. (18),No,( 8),2010, pp. 9931003.

19- Goodenough, Patrick Lawrence.," Ethical leadership, values congruence, and work place deviance: An exploratory study", PhD Dissertation , ( Webster University, April, 2008).
Geographical Context of Pakistan", International Journal of Business and Management, Vol. (4),No,( 1), 2009, pp: 85-92.

11- Chen, L., " Examining the Effect of Organization Culture and Leadership Behaviors on Organizational Commitment, Job Satisfaction, and Job Performance at Small and Middle-sized Firms of Taiwan ", Journal of American Academy of Business, Vol. (5),No,( 1/2), 2004, pp: 432438.

12- Cottrill, K.," Antecedents and Outcomes of Inclusion: Exploring Authentic Leadership, Organizational Climate for Ethics, Organization-Based SelfEsteem, and Organizational Citizenship Behaviors ", PhD Dissertation , ( Alliant International University, Los Angeles, California, December, 2011).

13- Dalal, R., " A Meta-Analysis of the Relationship Between Organizational Citizenship Behavior and Counterproductive Work Behavior ", Journal of Applied Psychology, Vol. (90),No,( 6), 2005, pp: 12411255.

14- Dunlop, P.\& Lee, K., " Workplace Deviance, Organizational Citizenship Behavior, and Business Unit Performance: The Bad Apples Do Spoil The Whole Barrel ", Journal of Organizational 
26- Luth, M., " The Bright And Dark Sides Of Empowerment: Linking Psychological Empowerment And Job Stressors To Proactive And Counterproductive Work Behaviors", PhD Dissertation ,( University of Kansas, July, 2012).

27- Mount, M.\& Ilies, R.\& Johnson, E., " Relationship Of Personality Traits And Counterproductive Work Behaviors: The Mediating Effects Of Job Satisfaction ", Personnel Psychology, Vol. (59),No,(3), 2006, pp: 591-622.

28- Peterson, D.," Deviant Workplace Behavior And The Organization's Ethical Climate. ", Journal of Business and Psychology, Vol. (17),No,(1), 2002, pp: 47-61.

29- Peterson, S.\& Walumbwa, F.\& Avolio, B.\& Hannah, S., "The Relationship Between Authentic Leadership And Follower Job Performance: The Mediating Role of Follower Positivity in Extreme Contexts", The Leadership Quarterly, Vol. (23),No,(3), 2012, pp.502-516.

30- Rader, Martha Milan.,"Effects of Authentic Leadership on Job Satisfaction and Younger Worker Turnover Intentions Title of your Document", PhD Dissertation ,( The Chicago School of Professional Psychology,

February, 2015).

31- Ratliff, R., " Effect of Organizational Climate on Job Performance and Employee Engagement", PhD Dissertation ,( Walden University, 2012).
20- Gruys, M.\& Sackett, P.," Investigating the Dimensionality of Counterproductive Work Behavior ", International Journal of Selection \& Assessment, Vol. (11),No,(1), 2003, pp: 30-42.

21- Halldórsson, F.," Leadership Style, Employee Job Performance, and Organizational Outcomes", PhD Dissertation ,(The Faculty of the graduate school of the University of Minnesota, 2008).

22- Kernis, M., " Toward a Conceptualization of Optimal Self-Esteem", Psychological Inquiry, Vol. (14),No,( 1), 2003, pp. 1-26.

23- Laschinger, H.\& Wong, C.\& Grau, A.," The Influence of Authentic Leadership on Newly Graduated Nurses' Experiences of Workplace Bullying, Burnout and Retention Outcomes: A cross-sectional study", International Journal of Nursing Studies, Vol. (49),No,(10), 2012, pp. 12661276.

24- Lau, V.\& Au, W.\& Ho, J.," A Qualitative and Quantitative Review of Antecedents of Counterproductive Behavior in Organizations ", Journal of Business and Psychology, Vol. (18),No,(1), 2003, pp: 73-99 .

25- Liu, Yan.," Linking authentic leadership to positive employee health, behavioral engagement, and job performance", PhD Dissertation ,( Louisiana Tech University, March, 2012). 
Processes Linking Authentic Leadership To Follower Behaviors", The Leadership Quarterly, Vol. (21),No,( 5), 2010, p901-914.

38- Walumbwa, F.\& Avolio, B.\& Gardner, W.\& Wernsing T.\& Peterson, S., " Authentic Leadership: Development and Validation of a Theory-Based Measure, "Journal of Management, Vol. (34),No,(1), 2008, pp. 89-126.

39- Wherry,

H.,"Authentic

Leadership, Leader-Member

Exchange, And Organizational

Citizenship Behavior: A Multilevel Analysis", PhD Dissertation ,(University of Nebraska, August, 2012).

40- Wong, C.\& Cummings, G., " The Influence Of Authentic Leadership Behaviors On Trust And Work Outcomes Of Health Care staff, " Journal Of Leadership Studies, Vol. (3),No,( 2), 2009, pp. 6-23.

41- Wood, G.," Authentic Leadership: Do We Really Need Another Leadership Theory?", PhD Dissertation ,( George Mason University, 2007).

42- Yemi-Sofumade, H., " The Relationship Between Ethical And Authentic Nurse , Leadership And The Turnover Intentions Of Staff Nurses ", PhD Dissertation ,( Capella University , March, 2012).
32- Rego, A.\& Vitória, A.\& Magalhães, A.\& Ribeiro, N.\& Cunha, M., " Are Authentic Leaders Associated With more Virtuous, Committed and Potent Teams? ", The Leadership Quarterly, Vol. (24), No,(1),2013, pp. 61-79.

33- Sackett, P.\& Berry, C.\& Wiemann, S.\& Laczo, R.," Citizenship and Counterproductive Behavior: Clarifying Relations Between the Two Domains ", Human Performance, Vol. (19),No,(4), 2006, pp: 441-464.

34- Spector, P.\& Fox, S.\& Penney, L.\& Bruursema, K.\& Goh, A.\& Kessler, S., "The Dimensionality Of Counterproductively: Are All Counterproductive Behaviors Created Equal?", Journal of Vocational Behavior, Vol. (68),No,(3), 2006, pp: 446-460.

35- Tapara, P., " Authentic Leadership: Organizational Outcomes and Leader and Follower Development" Master Thesis,( Massey University, Albany, 2011).

36- Tuttle, M., " True North or Traveled Terrain? An Empirical Investigation of Authentic Leadership", PhD Dissertation ,( College of Arts and Sciences, University of South Florida, November, 2009).

37- Walumbwa, F.\& Wang, P.\& Wang, H.\& Schaubroeck, J.\& Avolio, B.," Psychological 